\title{
Estudo de revisão sistemática sobre o uso do conceito de cotidiano no campo da Terapia Ocupacional na literatura de língua inglesa ${ }^{1}$
}

\author{
Mariana Moraes Salles $s^{\mathrm{a}, \mathrm{b}}$, Thelma Simóes Matsukura ${ }^{\mathrm{b}, \mathrm{c}, \mathrm{d}}$ \\ ${ }^{a}$ Escola de Enfermagem, Universidade de São Paulo - USP, São Paulo, SP, Brasil

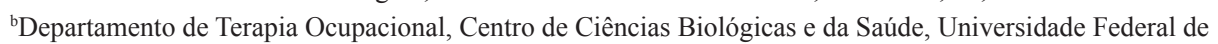 \\ São Carlos - UFSCar, São Carlos, SP, Brasil \\ 'Programa de Pós-graduação em Terapia Ocupacional, Centro de Ciências Biológicas e da Saúde, Universidade \\ Federal de São Carlos - UFSCar, São Carlos, SP, Brasil \\ dPrograma de Pós-graduação em Educação Especial, Centro de Educação e Ciências Humanas, Universidade \\ Federal de São Carlos - UFSCar, São Carlos, SP, Brasil
}

\begin{abstract}
Resumo: O presente estudo tem como objetivo identificar como o conceito de cotidiano é utilizado no campo da Terapia Ocupacional, na literatura de língua inglesa e tecer considerações em relação à literatura nacional sobre o assunto. Foi realizada uma revisão sistemática da literatura internacional sobre o conceito de cotidiano no campo da Terapia Ocupacional e, a partir dos resultados desta etapa, apresentam-se reflexões acerca de diferenças e similaridades observadas no uso do conceito no campo da Terapia Ocupacional no Brasil. Foram eleitos 20 artigos, selecionados a partir do Portal Periódicos Capes (Coordenação de Aperfeiçoamento de Pessoal de Nível Superior), para análise. Encontrou-se que os autores de língua inglesa, ao tratar da ruptura do cotidiano, focalizam no auxílio necessário para ajudar o sujeito a conseguir realizar suas ocupações anteriores, de forma autônoma. Além disso, a forma das pessoas viverem a vida cotidiana é um elemento constitutivo da identidade do sujeito, as pessoas se tornam o que são a partir de suas ocupações. O cotidiano é relatado em termos ocupacionais, a vida cotidiana é compreendida pelo que as pessoas fazem de significativo em suas vidas. Aponta-se que a literatura internacional não focaliza a relação do cotidiano com o contexto sociopolítico-cultural, como a literatura nacional. Assim, discute-se que a compreensão sobre o cotidiano contextualizado é comum aos terapeutas ocupacionais brasileiros e tem o potencial de se apresentar como um constructo em torno do qual se constrói a identidade da Terapia Ocupacional brasileira contemporânea.
\end{abstract}

Palavras-chave: Terapia Ocupacional, Cotidiano, Literatura de Revisão como Assunto.

\section{Systematic review about everyday life in Occupational Therapy English papers}

\begin{abstract}
The present study aims at identifying how the everyday life concept is used in the Occupational Therapy field in the English language literature and at making considerations in relation to the Brazilian literature on the subject. A systematic review of the international literature on the everyday life concept in the Occupational Therapy field was carried out and, from the results of this phase, reflections about the differences and similarities noticed in the use of this concept in the field of occupational therapy in Brazil are presented. Twenty articles selected from the CAPES (Coordination for the Improvement of Higher Education Personnel) database were elected for analysis. This analysis found that English speaking authors, on the issue of everyday life rupture, focus on the assistance needed to help individuals to be able to perform their former occupations in an autonomous way. Besides, the way people live their everyday lives is an element that constitutes the person's identity; people become what they are
\end{abstract}

Autor para correspondência: Thelma Simões Matsukura, Programa de Pós-graduação em Terapia Ocupacional, Centro de Ciências Biológicas e da Saúde, Universidade Federal de São Carlos, Rodovia Washington Luiz, Km 235, Monjolinho, CEP 13565-905, São Carlos, SP, Brasil. e-mail: thelmamatsukura@gmail.com; marianamsalles@gmail.com

Recebido em Mar. 31, 2014; Revisão em Ago. 7, 2014; Aceito em Out. 16, 2014. 
from their occupations. Everyday life is described in occupational terms; it is understood by the meaningful things people do in their lives. It is pointed out that, as opposed to the national literature, the international literature does not focus on the connection between everyday life and the social-political-cultural context. Thus, we discuss that the understanding about the contextualized everyday life is shared with Brazilian occupational therapists, and it has the potential to be presented as a construct on which the Brazilian contemporary occupational therapy identity is built.

Keywords: Occupational Therapy, Everyday Life, Review Literature as Topic.

\section{Introdução}

O que as pessoas fazem no seu dia a dia, como vivem a cotidianidade, é um fator que influencia diversas áreas da vida, estando intrinsecamente ligado aos processos de saúde e doença. De acordo com Salles e Barros (2007, p. 76), a saúde é um fenômeno complexo, que “[...] intervém na forma como o homem vive determinado espaço e tempo; como cada pessoa constrói um significado para a vida." É na vida cotidiana que as pessoas constroem a sua vida, se relacionam com os outros, fazem escolhas e participam dos processos produtivos. E é também na vida cotidiana que se desenvolvem os processos de saúde ou doença.

Para a maioria dos homens a vida é a vida cotidiana. A vida cotidiana é o conjunto de atividades que caracterizam a reprodução dos homens particulares, criando a possibilidade de reprodução social. Em toda sociedade há vida cotidiana, e todo homem tem uma vida cotidiana. A reprodução particular é reprodução de um homem concreto, que ocupa um lugar determinado na divisão social do trabalho (HELLER, 2002).

O ritmo ordinário da vida cotidiana é o mais profundo e primordial alimento para a existência de todas as pessoas. É a verdadeira, a realidade primária vivida pelos sujeitos. As ocupaçóes da vida cotidiana estáo sempre presentes na nossa vida, onde quer que seja. Elas são um meio primário pelo qual organizamos o mundo em que vivemos, a rede de padrôes interligados de ocupaçóes ordinárias ${ }^{2}$ é o que dá forma a nossa vida diária (HASSELKUS, 2006).

Além disso, o todo da vida cotidiana é composto de ocupaçóes, e o uso do tempo, os lugares de fazer e as rotinas habituais constituem aspectos definidos de todo estilo de vida (CHRISTIANSEN; TOWNSEND, 2010). Segundo Hasselkus (2006), ocupação cotidiana significa a experiência vivida na vida do dia a dia. O mundo da vida cotidiana é o mundo real, são as cenas familiares do cotidiano que são percebidas como "normais". A vida cotidiana é como uma âncora para a vida e é o ponto de partida e de chegada em todos os tipos de variaçóes que sáo colocadas na nossa vida diária.

Nesse contexto, levando-se em consideração a importância da vida cotidiana nos processos de saúde e doença, na singularidade do sujeito e na construção histórica da própria Terapia Ocupacional, o presente estudo tem como objetivo identificar como o conceito de cotidiano é utilizado no campo da Terapia Ocupacional, na literatura de língua inglesa e tecer considerações em relação à literatura nacional sobre o assunto.

\section{Metodologia}

Foi realizada uma revisão sistemática da literatura de língua inglesa ${ }^{3}$ sobre o conceito de cotidiano no campo da Terapia Ocupacional. Utilizou-se como questáo norteadora da pesquisa: Qual o desenvolvimento do uso do conceito de cotidiano em Terapia Ocupacional e como este conceito tem sido utilizado atualmente na literatura de língua inglesa?

A partir dos resultados desta revisão sistemática, busca-se refletir acerca de diferenças e similaridades observadas no uso do conceito no campo da Terapia Ocupacional no Brasil.

\subsection{Instrumentos}

Foi utilizado um formulário de avaliação para realizar a coleta de dados, e nele foram registrados os aspectos centrais de cada pesquisa. O formulário foi preenchido segundo os autores, ano de publicação, país onde o estudo foi realizado, a metodologia, as concepçóes do estudo em relação ao conceito de cotidiano, os principais resultados encontrados e considerações finais do estudo.

\subsection{Procedimentos}

A pesquisa na literatura explorou artigos completos, publicados nos últimos dez anos, no período de 2003 a 2012, em periódicos revisados por pares, publicados em língua inglesa, disponível 
em: Journals@Ovid, J-STAGE, EBSCO host CINAHL, Gale Cengage Academic, Elsevier Science Direct, EBSCO host Academic Search, DOAJ Directory of Open Access Journals; que foram acessados a partir do Portal Periódicos CAPES (Coordenação de Aperfeiçoamento de Pessoal de Nível Superior), e que pesquisaram ou abordaram o uso do conceito de cotidiano na área de conhecimento e atuação da Terapia Ocupacional.

No Portal Periódicos Capes é possível ter acesso às seguintes revistas de Terapia Ocupacional: The American Journal of Occupational Therapy; Asian Journal of Occupational Therapy; Australian Occupational Therapy Journal; British Journal of Occupational Therapy; The Canadian Journal of Occupational Therapy; Hong Kong Journal of Occupational Therapy I New Zealand Journal of Occupational Therapy I Occupational Therapy InternationalI The Open Journal of Occupational Therapy; e Scandinavian Journal of Occupational Therapy.

Foram utilizados como palavras-chave os termos occupational therapy em combinação com os termos everyday and everyday life. Foi utilizada a busca avançada no Portal Periódicos Capes, realizando-se a procura de textos que continham as palavras-chave no título.

Essa pesquisa inclui apenas artigos em inglês, pois o estudo de revisão envolvendo a literatura nacional foi realizado em pesquisa anterior e separadamente (SALLES; MATSUKURA, 2013).

Para seleção dos artigos foi realizada leitura do título e dos resumos segundo os seguintes critérios de inclusão: foram analisados estudos tanto quantitativos como qualitativos, ou estudos de revisão bibliográfica; estudos referentes a todas as áreas de atuação na Terapia Ocupacional, e sem limitaçóes em relação à idade da população estudada. Foram excluídos trabalhos que não eram referentes ao tema proposto, ou seja, que não utilizavam ou não faziam referência ao conceito de cotidiano. Também não foram utilizados editoriais, sumários, textos relacionados a apresentações em congressos, cartas, trabalhos publicados apenas na forma de resumos ou artigos onde não foi possível o acesso ao texto completo.

Foram excluídos os artigos que se referiam especificamente a atividades de vida diária, ou seja, em que o termo everyday se referia a everyday technology, relacionado à tecnologia usada em atividades de vida diária, ou everyday acitivities, relacionado a atividades de vida diária.
Após a leitura na íntegra dos trabalhos, eles foram avaliados com o objetivo de se verificarem os aspectos metodológicos e se os resultados da pesquisa seriam válidos para serem incorporados nesta revisão, no sentido de fornecerem elementos para análise acerca da temática sobre o cotidiano e Terapia Ocupacional.

Foi realizada uma síntese narrativa (GALVÃO; SAWADA; TREVIZAN, 2004), ou seja, uma síntese qualitativa, onde foram comparados os estudos selecionados procurando encontrar similaridades e diferenças na definição e no uso dos conceitos de cotidiano na literatura internacional referente à Terapia Ocupacional, realizando um diálogo com o que é proposto na literatura nacional.

A busca dos termos em inglês occupational therapy, everyday and everyday life em combinação, resultou em um total de 68 artigos. Após a leitura do título e resumo dos mesmos foram selecionados 20 artigos para análise.

\section{Resultados e discussão}

Apresentam-se na Figura 1, a seguir, informaçôes acerca dos periódicos onde os estudos considerados para análise foram localizados.

Referente ao local onde a pesquisa foi realizada, 14 estudos foram produzidos na Suécia, cinco nos Estados Unidos e um na Nova Zelândia. Para obter essa informação, pesquisou-se no corpo dos artigos se havia a indicação de onde a pesquisa tinha sido realizada, ou considerou-se a cidade de origem do primeiro autor como o local de produçáo do artigo. Portanto, 14 foram produzidos na Europa, cinco na América do Norte (Estados Unidos) e um no Oceano Pacífico Sul (Nova Zelândia).

$\mathrm{Na}$ Figura 2, apresentam-se as populaçóes da Terapia Ocupacional focalizadas nos estudos analisados.

A maior parte dos artigos foi publicada nos últimos cinco anos, com 11 artigos publicados entre 2008 e 2011, porém não houve nenhum artigo publicado nos últimos dois anos.

Dos 20 artigos analisados, 14 utilizaram a abordagem qualitativa nas pesquisas em pauta. Assim, sete estudos seguiam a abordagem fenomenológica, utilizando para a coleta de dados entrevistas e observação; duas pesquisas utilizavam o método hermenêutico-fenomenológico, fazendo uso de entrevistas individuais para coleta de dados; duas pesquisas utilizaram análise de conteúdo (entrevista e observaçáo participante foram os meios para a coleta de dados); havia dois estudos 


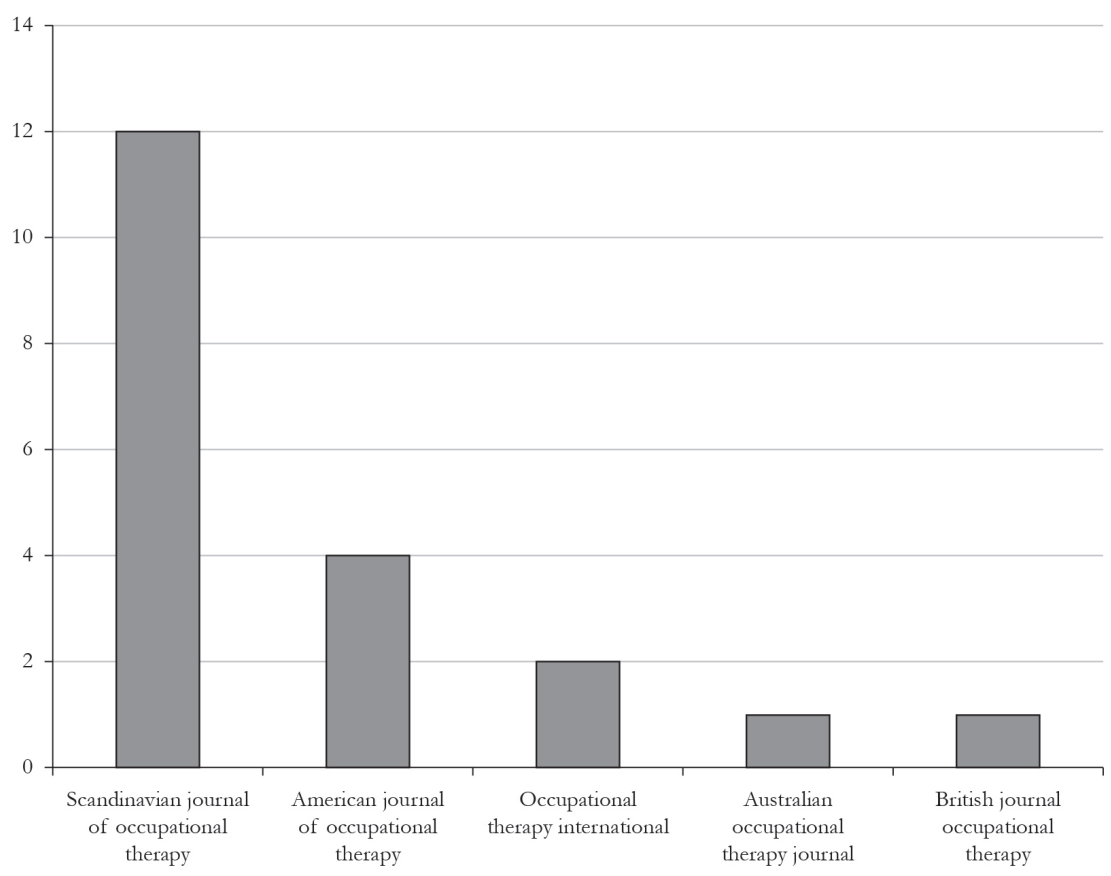

Figura 1. Número de publicações por revista, por número total de artigos analisados, Brasil - 2013. Fonte: Coleta de dados da autora, conforme descrito na metodologia.

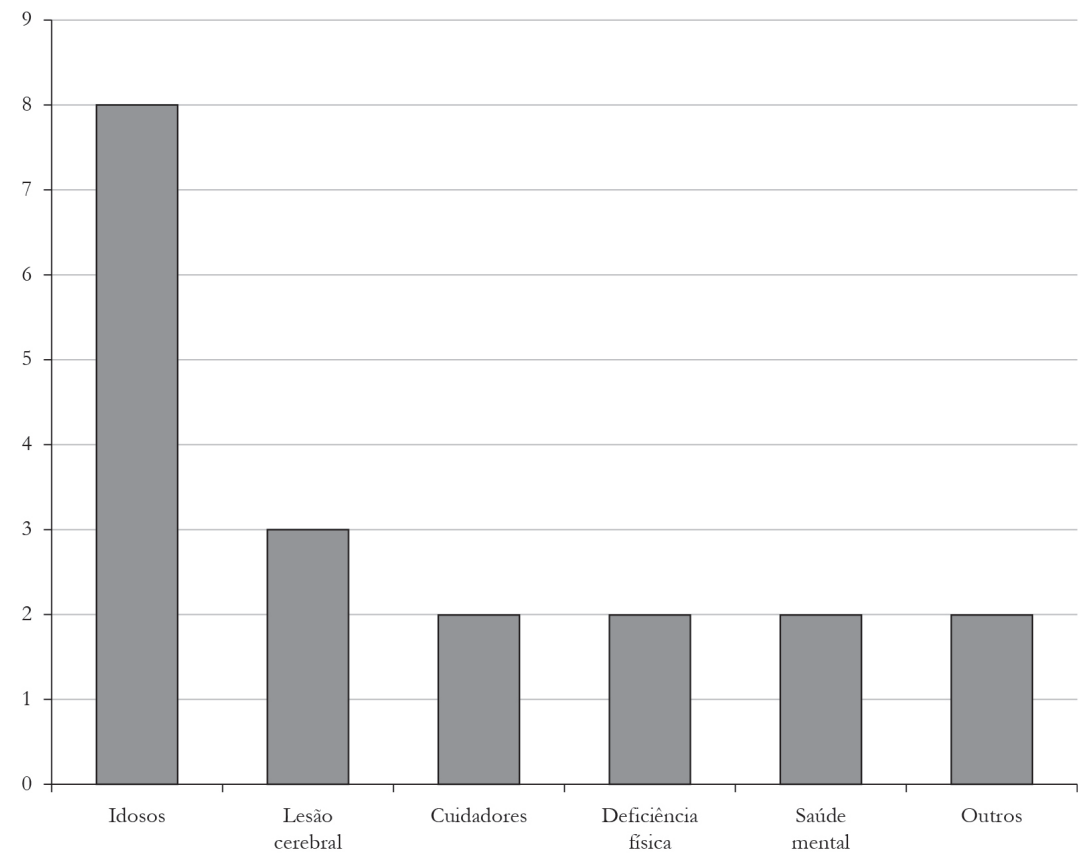

Figura 2. Número de temas principais dos estudos, por número total de artigos analisados, Brasil - 2013. Fonte: Coleta de dados da autora, conforme descrito na metodologia.

de caso (que usaram como recursos entrevistas, questionários e observação participante para coleta de dados) e um artigo utilizou a abordagem etnográfica, fazendo uso de entrevistas e observaçáo participante para coleta de dados.
Duas pesquisas faziam uso de abordagem qualitativa e quantitativa, utilizando questionário e entrevistas para coleta de dados. Três artigos utilizavam abordagem quantitativa, dois deles faziam uso de questionários e um utilizava Pager $^{4}$ 
para coleta de dados. Havia apenas um artigo de revisão de literatura do tipo narrativa.

Em consonância com esses resultados, em estudo de revisão sobre o conceito de cotidiano em Terapia Ocupacional na literatura nacional, identificou-se também o maior uso de abordagens qualitativas (SALLES; MATSUKURA, 2013). Considera-se a pertinência no uso de abordagens qualitativas em estudos referentes ao cotidiano, já que o cotidiano é vivido de forma individual e, em meio à concretude da vida de todo dia, as percepçôes da vida cotidiana abarcam diversas subjetividades sobre a identidade dos sujeitos, suas relaçóes pessoais e seus valores.

Três pesquisas náo definiam sobre o conceito de cotidiano. Apesar do termo "cotidiano" estar indicado nos artigos, esse conceito nâo fazia parte do referencial teórico da pesquisa (JOHANSSON; HOGBERG; BERNSPANG, 2007; DEGRACE, 2004; WERNGREN-ELGSTRÖM; BRANDT; IWARSSON, 2006).

Outras pesquisas não apresentaram uma definição sobre o conceito de cotidiano, mas afirmaram e/ou abordaram sobre a importância da vida cotidiana para uma determinada população ou em um contexto específico (ERIKSSON; THAM; FUGL-MEYER; 2005; WRIGHT-ST CLAIR; KERSE; SMYTHE, 2011; HASSELKUS; MURRAY, 2007; RABER et al., 2010; PERSSON; ZINGMARK, 2006; NÄTTERLUND, 2010).

Em outros estudos, a premissa adotada apontava que a experiência de encontrar significado nas ocupaçôes cotidianas é essencial para o bem-estar e qualidade de vida. A vida cotidiana é estudada a partir das ocupaçóes diárias dos participantes do estudo (LÖFQVIST et al., 2009; ÖHMAN; JOSEPHSSON; NYGARD, 2008; LARSSON; HAGLUND; HAGBERG, 2009; TOLLÉN; FREDRIKSSON; KAMWENDO, 2008; EKSTAM; THAM; BORELL, 2011; MARGOTCATTIN; NYGARD, 2006; ERLANDSSON; EKLUND, 2003; LINDÉN; BJÖRKLUND, 2010).

Alguns autores utilizaram o conceito de ocupaçáo como suporte teórico da pesquisa 5 . Nesses trabalhos, a ocupação é considerada como um constructo central no campo da Terapia Ocupacional, e o paradigma é que o engajamento em ocupaçôes influencia a saúde e o bem-estar (REILLY, 1962 apud EKSTAM; THAM; BORELL, 2011).

$\mathrm{Na}$ literatura de língua inglesa encontrou-se que um pressuposto teórico de base na Terapia Ocupacional é a relação dinâmica entre a pessoa, o ambiente e a ocupaçáo, que moldam o desempenho ocupacional (TOWNSEND; POLATAJKO, 2007 apud LÖFQVIST et al., 2009).

Percebe-se, nesses estudos, que o conceito centralizador das pesquisas é conceito de ocupação, que é considerado como algo bem descrito e fundamentado na literatura da área. Nesse contexto, o conceito de cotidiano aparece em relaçáo ao conceito de ocupação, nas descriçóes da vida "vivida" pelas pessoas, nos desdobramentos do dia a dia, nas significaçôes das ocupações na vida cotidiana.

As ocupações são o caminho utilizado pela literatura internacional para discutir a vida cotidiana, o conceito de ocupação é o meio utilizado nesses estudos para se refletir sobre o cotidiano dos sujeitos. Porém, cabe lembrar que não existe um consenso na literatura internacional sobre o conceito de ocupação, existem diferentes concepçóes e formas de compreender o conceito de ocupação que podem influenciar as percepções sobre o cotidiano dos sujeitos.

Wright-St Clair, Kerse e Smythe (2011) utilizaram a referência da terapeuta ocupacional Hasselkus (2006) para definir o conceito de cotidiano: os terapeutas ocupacionais podem compreender as ocupaçóes ordinárias no contexto da vida cotidiana. É pelo padrão de ocupaçôes cotidianas que as pessoas constroem a sua vida e vivenciam a vida comunitária. Nessa direção, Lindén e Björklund (2010) descreveram que o significado da vida cotidiana é cuidar de si mesmo, da família, da casa, trabalhar e participar de atividades de lazer.

Porém, Hasselkus (2006) não apenas define o conceito de cotidiano e discute-o em relaçáo à ocupação, como também reflete sobre os motivos que levam alguns terapeutas ocupacionais a não focalizar no conceito de cotidiano, ainda que se reconheça a importância desse conceito no âmbito da Terapia Ocupacional.

Para a autora, a vida cotidiana é um paradoxo na nossa vida. São os pequenos comportamentos que abarcam o campo da vida diária de cada um, é mais do que o que os sujeitos têm em comum, representa também a individualidade e distinção (HASSELKUS, 2006).

Hasselkus (2006) indica que a Terapia Ocupacional, na tentativa de definir a profissáo, dividiu o conceito de ocupação em três grandes dimensóes: trabalho, lazer e autocuidado. Este esquema simplifica a noção das ocupaçôes cotidianas, porém muitos significados da ocupação 
podem ser ignorados. Ao usar estas categorias fica mais fácil descrever e explicar as coisas, entretanto, corre-se o risco de perder a visão do que é único em cada contexto, da individualidade dos pequenos comportamentos, e a vida cotidiana pode ser varrida para essas categorias (HASSELKUS, 2006).

Na literatura brasileira, essa singularidade da vida cotidiana também é colocada em foco pelos autores nacionais que estudam o conceito de cotidiano. Em estudo de revisão da literatura nacional envolvendo a Terapia Ocupacional e o cotidiano, identificou-se que existe a preocupação em usar o cotidiano para evidenciar a vida cotidiana individual, mas sempre em relaçáo ao contexto social em que o sujeito vive (SALLES; MATSUKURA, 2013). Observou-se que o contexto social do sujeito pode incluir o sistema político e jurídico, as formas de produção social, a cultura da sua comunidade, as desigualdades sociais e as possibilidades do sujeito em exercer a sua cidadania.

De acordo com Hasselkus (2006) é difícil ter uma linguagem para descrever a cotidianidade, pois as palavras relacionadas ao diário, como elementar, ordinário, familiar, usual, são palavras que não têm poder, são desvalorizadas. Segundo a autora, existe uma desvalorizaçáo da cotidianidade na sociedade. Os valores centrais, a essência das pessoas está imersa na vida cotidiana, mas estes valores e este foco, provavelmente, não irão gerar muita atenção no poder de influência na nossa sociedade.

A hipótese da autora é de que o pouco enfoque dado pelos terapeutas ocupacionais ao conceito de cotidiano reside no fato de que os terapeutas ocupacionais não querem focalizar o ordinário e familiar, pois existe o desejo de ser um profissional respeitado, que tem uma voz que será ouvida, que será considerado como altamente qualificado, e náo como uma pessoa pouco articulada da prática ordinária e mundana (HASSELKUS, 2006).

Nesse aspecto, a literatura nacional se distancia da literatura anglófona, já que o conceito de cotidiano é valorizado por profissionais e acadêmicos e a Terapia Ocupacional brasileira se mostra interessada em compreender e usar o conceito de cotidiano. O cotidiano pode ser considerado um conceito que vem sendo foco de estudo há longo tempo por pensadores e filósofos reconhecidos pela academia, e não existe desprestígio na continuidade do estudo desse conceito. Conforme relata Galheigo (2003, p. 106), "[...] a vida cotidiana se constitui como um objeto de reflexão filosófica."

Compreende-se que a Terapia Ocupacional brasileira se aproxima da compreensão de Hasselkus
(2006) de que a premissa é que as pequenas experiências da vida cotidiana e as ocupaçóes cotidianas são complexas, bonitas, significativas e são relevantes para a saúde e bem-estar, apesar de escondidas na áurea da rotina e da ordinariedade. Não obstante, a hipótese da autora acerca da desvalorizaçáo da vida do dia a dia, do que é habitual, deve encontrar respaldo nas questôes culturais e políticas dos países ocidentais, em geral, e no país de origem da autora (Estados Unidos), em particular, o que também pode explicar diferenças entre as concepçóes e o forte interesse no conceito de cotidiano observado na Terapia Ocupacional brasileira.

\section{Ruptura ocupacional}

Nos artigos que se propóem a estudar o cotidiano, as transformaçóes na vida cotidiana proporcionadas pelo o início de uma doença são marcantes, sendo evidente uma mudança nos padrōes das ocupaçóes do sujeito. A literatura nacional sobre o conceito de cotidiano também enfatiza essa ruptura da vida cotidiana após o início de uma doença (SALLES; MATSUKURA, 2013). Não obstante, problematiza-se o fato de que a ruptura na vida cotidiana só faz sentido se entendida como uma mudança radical, uma transformaçáo abrupta e não esperada pelo sujeito; ela não é considerada como a interrupção do cotidiano, pois o cotidiano não deixa de existir.

Verificou-se na literatura de língua inglesa que com a doença ou a idade avançada, os sujeitos foco dos estudos não conseguem mais desempenhar algumas atividades como antes, e param de participar destas ocupaçóes (LARSSON; HAGLUND; HAGBERG, 2009; TOLLÉN; FREDRIKSSON; KAMWENDO, 2008; NÄTTERLUND, 2010). É possível que a vida cotidiana se deteriore, seguindo uma direção negativa. Como consequência, as pessoas vivenciam limitações na vida familiar, no trabalho e no contexto social (LINDÉN; BJÖRKLUND, 2010; NÄTTERLUND, 2010). As ocupações que eram consideradas ordinárias e garantidas se tornam extraordinárias e não garantidas (HASSELKUS; MURRAY, 2007).

Nesse contexto, é possível que as pessoas tenham uma experiência de mal-estar, que é descrita em termos ocupacionais (HASSELKUS; MURRAY, 2007). As consequências da doença são expressas como mudanças nas ocupaçóes que transformam a sua vida cotidiana, sua interação com outras pessoas e com o ambiente social (ÖHMAN; 
JOSEPHSSON; NYGARD, 2008; DEGRACE, 2004).

Porém, essas disrupturas também levam ao desenvolvimento de novas habilidades e novos vínculos com a família e a comunidade (HASSELKUS; MURRAY, 2007). Na tentativa de diminuir o impacto da doença na vida cotidiana e evitar disrupturas, as pessoas tentam criar novas formas de fazer e viver a vida cotidiana e procuram se adaptar à situação, sem que isso cause uma disruptura no cotidiano.

Os sujeitos tentam manejar as mudanças nas ocupações adotando abordagens adaptativas em seu desempenho e em suas interaçóes sociais (ÖHMAN; JOSEPHSSON; NYGARD, 2008). Eles vivenciam um processo de ajustamento à nova situação de vida (PERSSON; ZINGMARK, 2006). Também recebem orientaçóes de especialistas sobre como adaptar a casa e usar tecnologias para tornar as atividades cotidianas mais fáceis (NÄTTERLUND, 2010).

Há o posicionamento de que, em alguns contextos, o que muda não é o que a pessoa faz, mas a forma de fazer. Estar ocupado é importante, mesmo que o fazer seja adaptado e demore mais do que anteriormente (LARSSON; HAGLUND; HAGBERG, 2009).

Os autores dos artigos, ao tratar da ruptura do cotidiano, focalizam em ajudar o sujeito a voltar a conseguir realizar a ocupação, em ter a habilidade de fazer, em adaptar o ambiente, a ocupação ou o sujeito para tornar o fazer viável novamente. Já na literatura brasileira, como apontam Salles e Matsukura (2013, p. 270), existe uma atençáo importante para que o sujeito possa ressignificar a vida cotidiana,

[...] buscar na vida antes do adoecimento sentido para sua vida, mas também encontrar novos caminhos de construção da sua subjetividade, de quem ele é, o que gosta de fazer, como participa dos modos de produção social e com quem se relaciona.

\section{Possibilidades de fazer}

Apesar da doença ou idade avançada e da disruptura na vida cotidiana, os sujeitos se esforçam para continuar ativos e para se envolver em ocupaçóes que sejam significativas para eles (LARSSON; HAGLUND; HAGBERG, 2009; TOLLÉN; FREDRIKSSON; KAMWENDO, 2008; JOHANSSON; HOGBERG; BERNSPANG, 2007; NÄTTERLUND, 2010).
Para os idosos, por exemplo, é importante sair de casa todos os dias, pois se sentem ativos fisicamente, e a vida cotidiana consiste nas coisas ordinárias que eles sempre fazem. Fazer coisas foi descrito como algo que os deixava felizes, que ajudava a esquecer das dores (LARSSON; HAGLUND; HAGBERG, 2009).

Para descrever a vida cotidiana dos sujeitos, os autores consideraram útil adotar áreas da ocupação, como trabalho, lazer, autocuidados e atividades sociais. Essa forma de organizar o fazer cotidiano traz o foco da pesquisa para o conceito de ocupação.

Por exemplo, em pesquisa com idosos, foram relatadas as atividades que eles continuam realizando na vida cotidiana, como autocuidado e cuidados com a casa, atividades de lazer, atividades sociais e físicas (TOLLÉN; FREDRIKSSON; KAMWENDO, 2008; LARSSON; HAGLUND; HAGBERG, 2009).

O estudo de Johansson, Hogberg e Bernspang (2007) relata que as pessoas com lesâo cerebral têm limitaçóes para participar de ocupaçóes cotidianas. A área que eles se sentiam mais confortáveis em realizar ocupaçóes era a relacionada com cuidados pessoais, seguida das atividades recreacionais e sociais, e a área com o menor nível de participação foi a que comportava as atividades relacionadas ao trabalho.

Essas categorias podem ser consideradas úteis para decompor e desdobrar a vida cotidiana, sendo possível refletir sobre as particularidades de cada população em relação a estas atividades (JOHANSSON; HOGBERG; BERNSPANG, 2007; ERIKSSON; THAM; FUGL-MEYER, 2005; LARSON; EYE, 2010; LINDÉN; BJÖRKLUND, 2010; NÄTTERLUND, 2010).

Também foi relatada a importância para os sujeitos de ter a capacidade e liberdade para gerir sua própria vida cotidiana, sendo ressaltada a relevância em se fazer escolhas. Apesar da valorização das ocupaçóes que são realizadas junto com outras pessoas, é significativo ter a potencialidade e possibilidade de realizar as ocupaçóes sozinho, o que pode contribuir para a manutençáo da independência (LARSSON; HAGLUND; HAGBERG, 2009; LINDÉN; BJÖRKLUND, 2010; NÄTTERLUND, 2010). Nesta direção, há a compreensão de que a independência é a habilidade do sujeito de participar das ocupaçōes necessárias ou escolhidas de forma satisfatória; podendo para isso fazer uso de um ambiente adaptado ou modificado, ou utilizar dispositivos e estratégias alternativas (CARLETO et al., 2010). 
Para idosos é importante estar física e mentalmente bem, para continuarem independentes, morando sozinhos e manejando o cotidiano sozinhos, apesar do esforço necessário para a realização das ocupaçóes (LARSSON; HAGLUND; HAGBERG, 2009). Ser independente nas ocupaçôes significava poder escolher se e quando realizá-las, sem precisar esperar pela disponibilidade de outra pessoa (TOLLÉN; FREDRIKSSON; KAMWENDO, 2008).

Para manter a autonomia na vida cotidiana as pessoas precisam ser capazes de realizar as ocupaçóes cotidianas, sendo importante manter a potencialidade de fazer coisas.

A sensação de capacidade ou efetividade é evidente nas expressões de confiança ou dúvida durante a realização de atividades cotidianas (RABER et al., 2010). No estudo de Nätterlund (2010), os participantes descrevem sua capacidade em algumas atividades, mesmo que demorem mais em sua execução, como nas atividades de autocuidado e cuidados com a casa.

Um dos recursos utilizados para manter a autonomia na vida cotidiana foi o uso de tecnologias que permitiam às pessoas com deficiência ou idosos manterem a capacidade para executar a atividade. $\mathrm{O}$ uso de recursos tecnológicos é uma mudança no contexto em que vive a pessoa, que facilita para que o sujeito continue na condução da sua vida.

Para que idosos continuassem a realizar suas ocupaçóes também foram usados dispositivos de tecnologia assistiva, foram realizadas modificaçóes na casa, serviço residencial ou eles recebiam ajuda de outra pessoa (TOLLÉN; FREDRIKSSON; KAMWENDO, 2008; MARGOT-CATTIN; NYGARD, 2006; LÖFQVIST et al., 2009; NÄTTERLUND, 2010).

Além disso, de uma forma geral, percebeu-se nos artigos que existe a preocupação em demonstrar como as ocupaçóes da vida cotidiana geram processos de saúde ou doença. $\mathrm{O}$ que as pessoas fazem, como elas vivem são aspectos que interferem no desenvolvimento das doenças.

Os estudos convergem no pressuposto de que uma atitude positiva em relação às ocupaçôes após o adoecimento ou início de deficiência, por exemplo, como permanecer ativo e sentir prazer nas ocupaçóes, é importante para o desenvolvimento da qualidade de vida e saúde física e mental (EKSTAM; THAM; BORELL, 2011; TOLLÉN; FREDRIKSSON; KAMWENDO, 2008; LINDÉN; BJÖRKLUND, 2010). Porém, a falta de participação nas ocupaçóes pode causar sintomas de doenças e depressão (WERNGREN-ELGSTRÖM; BRANDT; IWARSSON, 2006).

Outros elementos do cotidiano, como o tempo, também foram focalizados. O estudo de Larson e Eye (2010) descreve como a pressão e a falta de tempo afetam a qualidade de vida, e indicam o quão é importante conhecer a temporalidade relacionada às atividades cotidianas.

Assim, é possível observar que os estudos, ao abordar o cotidiano, estão focalizando as ocupaçóes: as alteraçóes, adaptaçóes e/ou dificuldades em efetivá-las.

\section{Relações sociais e vida cotidiana}

A vida cotidiana dos sujeitos está em conexão com a vida cotidiana das pessoas a sua volta. Os cotidianos se entrelaçam, as ocupaçóes são compartilhadas, o que acontece com uma pessoa afeta aqueles que estão ao seu redor; os modos de fazer de uma pessoa influenciam e são influenciados pelos modos de fazer das pessoas a sua volta. Quando a vida cotidiana está entrelaçada com a vida de outra pessoa, além de ser significativo o que faz junto com a outra pessoa, ou seja, as ocupaçóes compartilhadas, o que se faz separadamente também afeta a vida cotidiana dos sujeitos; realizar uma tarefa por uma pessoa, por exemplo, muda seu cotidiano, entre outros.

Por exemplo, a satisfação com a vida está significantemente relacionada com o funcionamento do casal (em que uma pessoa teve uma lesão cerebral) na vida cotidiana, principalmente com a percepçáo do casal sobre o tempo de lazer, vida social e habilidades em atividades da vida diária (ERIKSSON; THAM; FUGL-MEYER, 2005). O esforço para reorganizar a vida cotidiana após o adoecimento é feito pelo paciente, mas também pelos seus familiares (EKSTAM; THAM; BORELL, 2011; NÄTTERLUND, 2010).

As reações, a forma das pessoas da rede social do sujeito em lidar com as dificuldades em participar de ocupaçōes da pessoa que adoeceu podem ser cruciais na possibilidade dessa pessoa em se manter ativa e na conduçâo da vida cotidiana. É significativo se a atitude da rede social é de: se afastar da pessoa, pois ela já não consegue realizar as ocupaçóes que fazia antes; fazer pela pessoa, limitando as oportunidades destas pessoas de fazer; ou se oferecem suporte e dão espaço para que a pessoa possa desenvolver suas 
potencialidades e participar de diferentes ocupaçôes (EKSTAM; THAM; BORELL, 2011).

$\mathrm{O}$ senso de reciprocidade entre cuidador e a pessoa que recebe os cuidados também foi expresso como especialmente satisfatório, como, por exemplo, na sensação de receber um abraço ou ouvir "eu te amo" da pessoa com demência após prepará-la para dormir, ou simplesmente segurar as mãos enquanto caminham (HASSELKUS; MURRAY, 2007). No estudo de Persson e Zingmark (2006), os participantes descreveram prazer, dignidade e proximidade ao estar e fazer coisas junto com o parceiro. É significativo promover a participaçáo e o divertimento do parceiro em uma ocupação que ele tinha interesse no passado.

Mas o contato com outro também pode ser estressante, nem sempre é fácil compartilhar ocupaçôes, e principalmente viver uma vida cotidiana entrelaçada com a de outra pessoa. Persson e Zingmark (2006) apontam a importância de fazer coisas sem o parceiro, foi acentuada a necessidade de ter tempo para descansar, relaxar e participar de uma ocupação significativa individualmente. Ao criar esse espaço pessoal, eles podiam esquecer a doença por um tempo e "recarregar as baterias". Porém, ter tempo para as suas próprias atividades é difícil quando a sua vida cotidiana está entrelaçada com a da pessoa com Alzheimer.

A habilidade de interagir com outras pessoas influencia o desempenho e facilita a interação social durante a atividade. Quando as atividades cotidianas são planejadas e desempenhadas junto com outras pessoas existe a possibilidade de promover interaçáo social e a participação (YILMAZ et al., 2008).

Participar de ocupaçóes comunitárias também é significativo, fazer parte de um grupo, e fazer da mesma forma que o contexto social em que a pessoa está inserida faz tem o potencial de causar bem-estar, satisfação e o senso de comunhão com o coletivo.

Por exemplo, para os idosos surdos é importante participar da comunidade dos surdos e desenvolver atividades em um contexto em que é usada a linguagem de sinais (WERNGREN-ELGSTRÖM; BRANDT; IWARSSON, 2006).

Wright-St Clair, Kerse e Smythe (2011) também indicam que os idosos maori (povo nativo da Nova Zelândia) vivenciavam um profundo senso de propósito quando participam das ocupaçóes da comunidade e fazem parte do coletivo. Para os idosos não maori, o senso de propósito aparecia ao contribuir para os membros da família mais próxima ou individualmente.

Assim, verifica-se que além do enfoque na ocupação (engajamento, compartilhamento etc.), tem-se que, ao abordar sobre os temas relacionados ao cotidiano, ocupações, interação e participação social, os estudos abrangem contextos e situações em enfoque micro, ou seja, no casal, família, comunidade próxima. Não se observa uma preocupação ou olhar macro, diferentemente de alguns estudos brasileiros onde, mesmo a partir do enfoque cotidiano-ocupaçóes, discutem-se realidades socioeconômicas, o alcance ou limites de políticas públicas, dentre outros, que estão presentes e que compóem a complexidade do dia a dia (GALHEIGO, 2011; LUVIZARO; GALHEIGO, 2003; LOPES; GARCIA, 2010).

\section{A rotina e tempo cotidiano}

A rotina, a vida cotidiana que se repete, por um lado, pode causar a sensaçáo de tédio e vazio, de mesmice e falta de ocupaçóes interessantes. A vida cotidiana pode ser aprisionada na rotina, sem espaço para que ocorram mudanças. Por outro lado, a rotina pode ser um elemento que ajuda as pessoas a se organizarem, a ter a sensação de continuidade da vida, e se sentirem seguras em relação às ocupaçôes que realizam todos os dias.

Por exemplo, idosos relataram que a habilidade reduzida significava menores oportunidades de preencher o dia com atividades significativas, resultando na sensação de vazio, e um dia a dia sempre igual (TOLLÉN; FREDRIKSSON; KAMWENDO, 2008). Segundo Francisco (2001, p. 76), o cotidiano não é rotina, pois a rotina se refere a "[...] simples repetição mecânica de açóes que levam a um fazer por fazer". A rotina, compreendida nesse sentido, se refere a um cotidiano alienado (HELLER, 2000), que diminui o poder dos sujeitos de fazer suas próprias escolhas.

Nessa direção, existem outras formas de compreender a rotina, por exemplo, para idosos (sem disfunção física ou mental severa) ter uma rotina é significativo, pois se estabelece uma continuidade entre passado, presente e futuro na vida cotidiana. O fato de ser idoso não é necessariamente limitador, pois a vida cotidiana se estabelece a partir de ocupaçóes confortáveis e familiares da rotina (WRIGHT-ST CLAIR; KERSE; SMYTHE, 2011). A vida cotidiana de 
pessoas com afasia também é construída em torno de rotinas (NÄTTERLUND, 2010).

Alguns estudos indicam que o modo de fazer que se repete dia após dia, ano após ano, geração após geração, se torna imbuído de significados para os sujeitos, e repetir esses modos de fazer na vida cotidiana cria uma conexáo entre o tempo passado, presente e futuro. As atividades que a pessoa costumava fazer junto com outros, antes do adoecimento, podem ser um elo de conexão entre as pessoas ao longo do tempo.

Algumas ocupaçóes ajudam os idosos a relembrar e se conectar com eventos do passado. Para idosos maori, continuar fazendo os cerimoniais de seus antepassados é significativo, pois os situa em seu contexto (WRIGHT-ST CLAIR; KERSE; SMYTHE, 2011).

As expressóes de interesse de idosos frequentemente são refletidas em atividades que eles tinham interesse no passado; eles procuram manter essas atividades mesmo que não as realizem completamente (RABER et al., 2010).

\section{Identidade}

A forma de as pessoas viverem a vida cotidiana é um elemento constitutivo da identidade do sujeito, as pessoas se identificam com o que fazem, e se tornam o que são a partir de suas ocupações.

O significado de ser idoso se apresenta na ordinariedade da vida cotidiana. Assim, no estudo de Wright-St Clair, Kerse e Smythe (2011), os idosos percebem a fraqueza, a dificuldade e velhice ao tentar realizar ocupaçóes que costumavam ser familiares e que se tornam desconfortáveis e pouco familiares, e se reconhece que a idade se anuncia quando, de repente, não se consegue mais realizar as ocupaçóes cotidianas.

A identidade dos familiares de crianças autistas é focalizada por DeGrace (2004) ao revelar que existe um sentimento de tristeza na família com uma criança autista pela dificuldade de sentir uma unidade familiar e viver uma vida cotidiana em família, como outras famílias que não têm uma criança com autismo. Eles têm dificuldade de sentir que são uma família e a identidade da família se torna o autismo.

Nesse sentido, percebe-se, na literatura internacional, que o engajamento em ocupaçóes é reconhecido como um componente vital da expressão de quem a pessoa é (HASSELKUS; MURRAY, 2007).

\section{Vida cotidiana e a atenção em Terapia Ocupacional}

A vida cotidiana pode ser entendida como um elemento de relevância na atenção à saúde das pessoas. Se as ocupaçôes da vida cotidiana podem gerar processos de saúde ou doença, elas devem ser vistas como uma parte importante no tratamento das pessoas.

A vida cotidiana pode ser um ponto de partida para açóes em Terapia Ocupacional (TOLLÉN; FREDRIKSSON; KAMWENDO, 2008; ERLANDSSON; EKLUND, 2003). Os terapeutas ocupacionais podem criar um contexto cotidiano que ofereça suporte para a pessoa em seu engajamento em ocupaçôes. Podem ser realizadas, por exemplo, a simplificação da tarefa ou a orientação ao marido ou esposa da pessoa, melhorando suas interaçóes sociais (ÖHMAN; JOSEPHSSON; NYGARD, 2008).

Para Tollén, Fredriksson e Kamwendo (2008), os terapeutas ocupacionais devem ajudar os pacientes, que perderam a possibilidade de participarem de ocupaçóes, a descobrirem novas ocupaçôes significativas e introduzir espaços alternativos de encontro onde a socialização não demande muito da pessoa.

Mesmo que pareça mais fácil manter o foco em restaurar funçôes e trabalhar a independência nas atividades de vida diária, o processo terapêutico deve ser significativo para o paciente, o foco deve ser mantido na ocupação, e as atividades terapêuticas devem ser incorporadas na vida das pessoas (EKSTAM; THAM; BORELL, 2011; LÖFQVIST et al., 2009).

Também foi apontada a necessidade de se dar atenção não apenas para a vida cotidiana do sujeito atendido em Terapia Ocupacional, mas também das pessoas da sua rede social. Considerando que as pessoas vivem cotidianos entrelaçados e a importância das ocupaçóes realizadas de forma compartilhada com outros, a atenção em Terapia Ocupacional deve ser proposta não apenas para o sujeito, mas também para a família e pessoas significativas na sua vida cotidiana. Assim, é importante focar no funcionamento da família como um todo, e os parceiros dos pacientes devem ser incluídos no processo de reabilitação (ERIKSSON; THAM; FUGL-MEYER, 2005; EKSTAM; THAM; BORELL, 2011; DEGRACE, 2004; PERSSON; ZINGMARK, 2006). 
10 O cotidiano na literatura

\section{nacional e internacional da Terapia Ocupacional: tecendo reflexões e considerações}

Diferentemente dos autores brasileiros, que se respaldaram em autores da filosofia para definir o conceito de cotidiano, os estudos selecionados na amostra deste artigo utilizaram autores terapeutas ocupacionais como referencial, e o conceito de ocupação aparece de forma centralizadora; sendo o conceito de cotidiano, muitas vezes, um conceito marginal ao conceito de ocupação.

A literatura investigada no presente artigo náo deixa explícita a relação do cotidiano com a visão macro da sociedade, com o contexto socia, como a literatura nacional. Não são feitas relações de como o sistema social, as formas de produção, as políticas públicas ou serviços de saúde causam impacto na vida cotidiana dos sujeitos.

Na literatura anglófona, o social é compreendido a partir das particularidades dos sujeitos, o foco está nas relaçóes sociais mais imediatas da pessoa, nos cotidianos entrelaçados do sujeito com as pessoas $\mathrm{da}$ sua rede social. Nesse sentido, o social fica restrito a um mundo privado e particular.

Ainda que esse foco também esteja presente na literatura nacional, observa-se a amplitude nos estudos de autores brasileiros, onde, por exemplo, ao se levantarem questóes temáticas nos cotidianos, envolvem e debatem políticas públicas, condições sociais, econômicas, culturais, entre outras (GALHEIGO, 2011; LUVIZARO; GALHEIGO, 2003; LOPES; GARCIA, 2010).

Além disso, o cotidiano é relatado em termos ocupacionais, a vida cotidiana é compreendida pelo o que as pessoas fazem de significativo em suas vidas. O cotidiano é entendido por meio do fazer e das expressôes da ocupação: enquanto um facilitador para a vida social, enquanto constituição da identidade, possibilidade de manter a autonomia, e de constituir a saúde. A ocupação é célula básica da vida cotidiana. É o elemento centralizador em torno do qual a vida cotidiana se organiza.

Apesar de existir a indicação de que a Terapia Ocupacional não deve acontecer apenas dentro de um "laboratório", e de que a clínica deve se estender para a vida cotidiana das pessoas, muitas vezes a visão da literatura internacional se aproxima de uma compreensão de caráter mais positivista, e não evidencia a preocupação em compreender o sujeito como um ser histórico, inserido em um determinado contexto social.

Dessa forma, na literatura internacional o cotidiano não se apresenta como um conceito que sustenta e direciona uma nova perspectiva teórica e metodológica da profissáo, como na literatura nacional; que usa o conceito de cotidiano para

[...] ir além do estudo dos fenômenos concretos, repetitivos e sintomáticos (como utilizado no paradigma médico), para focalizar também no que é único e ocorre em conexão com o contexto social [...] (SALLES; MATSUKURA, 2013, p. 269).

Assim, na literatura selecionada neste artigo, o cotidiano também é visto como um meio de preservar a individualidade e de, apesar das adversidades e rupturas da vida, se manter as ocupaçóes do sujeito, conservando os aspectos da vida cotidiana que o sujeito considera como significativo e, principalmente, resguardando as possibilidades de fazer.

Porém, na literatura nacional, o cotidiano não é visto apenas com o enfoque em se manter ou preservar as ocupaçóes, o cotidiano é compreendido também como possibilidade de transformar a vida do sujeito de forma positiva. Que o sujeito possa, na vida cotidiana, ser o protagonista da sua própria história, sendo capaz de fazer escolhas, de trabalhar, ser autônomo, ser respeitado na individualidade e diferença, e conduzir a sua vida cotidiana.

Entretanto, ainda é um desafio para a clínica da Terapia Ocupacional tornar claro e evidente como promover essa transformação, mesmo que ao longo de sua história a prática clínica tenha procurado empoderar ${ }^{6}$ os sujeitos, e acompanhar seus clientes na construçáo de novas formas de viver a vida.

Como relata Heller (2000, p. 40), a

[...] conduçáo da vida supóe, para cada um, uma vida própria, embora mantenha-se a estrutura da cotidianidade; cada qual deverá apropriar-se a seu modo da realidade e impor a ela a marca da sua personalidade.

Ainda que existam várias abordagens na literatura nacional, essa visão contextualizada sobre o cotidiano é contemporânea da Terapia Ocupacional brasileira. Existe o enfoque em como, apesar das doenças e dificuldades da vida, é possível para o sujeito conduzir sua própria vida e ser um ser social, a partir da realidade em que vive. $\mathrm{Na}$ reflexão sobre a vida cotidiana interessa que o sujeito possa atingir a sua potencialidade, dentro da sua individualidade, a partir das possibilidades 
e desafios presentes no contexto social. O olhar sobre o cotidiano se coloca na articulação dos aspectos singulares e sociais do sujeito, delimitados por um determinado espaço e tempo, ou seja, um determinado processo histórico e social.

Essa compreensão sobre o cotidiano parece comum aos terapeutas ocupacionais brasileiros e tem o potencial de dar forma para a profissão, sendo o constructo em torno do qual se constitui parte da identidade da Terapia Ocupacional brasileira contemporânea. $\mathrm{O}$ conceito de cotidiano pode ser colocado, então, como um paradigma da Terapia Ocupacional, que guia a teoria e prática da profissão, sendo um dos objetivos da Terapia Ocupacional brasileira a construção e reflexão sobre o cotidiano das pessoas que atende.

Como uma limitação do estudo, aponta-se a dificuldade de tradução dos termos nas diferentes línguas e as influências dos processos históricos no desenvolvimento da Terapia Ocupacional nos distintos países.

Essa limitação tem sido debatida na literatura em relação ao conceito de ocupação, conforme relatam Magalhães e Galheigo (2010). Porém existem poucos estudos que refletem sobre como as diferenças na linguagem, na cultura, e no contexto social entre os países afetam o conceito de cotidiano.

\section{Considerações finais}

O presente estudo respondeu aos objetivos propostos, realizando uma revisão de literatura da língua inglesa, articulando seus principais achados com a literatura nacional. Porém, no Brasil ainda se publica pouco sobre o tema, e existem questóes e reflexôes que podem ser apontadas para novos estudos, como, por exemplo, esmiuçar e esclarecer como articular o conceito de cotidiano à prática da Terapia Ocupacional. Assim, indica-se a necessidade de estudos clínicos que coloquem em foco as transformaçóes na vida cotidiana dos sujeitos em relaçáo ao processo em Terapia Ocupacional.

Também é sugerida a realização de estudos que possam refletir sobre a articulação entre os conceitos de cotidiano e ocupação, já que o presente artigo identificou a importância do conceito de ocupação na concepçáo de cotidiano para a Terapia Ocupacional ocidental.

A expectativa é que os resultados deste estudo de revisão e as reflexôes apresentadas possam contribuir para o debate e para acrescentar elementos acerca dos fundamentos de Terapia Ocupacional, e que possam fornecer elementos para investigaçóes futuras e para as proposiçôes de práticas da Terapia Ocupacional em diversos campos.

\section{Referências}

CARLETO, D. G. S. et al. Estrutura da prática da terapia ocupacional: domínio e processo. Revista Triângulo, Uberaba, v. 3, n. 2, p. 57-147, 2010.

CHRISTIANSEN, C. H.; TOWNSEND, E. A. An introduction to occupation. In: CHRISTIANSEN, C. H.; TOWNSEND, E. A. Introduction to occupation the art and science of living. $2^{\text {nd }} \mathrm{ed}$. New Jersey: Pearson, 2010. p. 1-34.

DEGRACE, B. W. The everyday occupation of families with children with autism. American Journal of Occupational Therapy, Bethesda, v. 58, n. 5, p. 543-550, 2004. http://dx.doi.org/10.5014/ajot.58.5.543

EKSTAM, L.; THAM, K.; BORELL, L. Couples' approaches to changes in everyday life during the first year after stroke. Scandinavian Journal of Occupational Therapy, Stockholm, v. 18, n. 1, p. 49-58, 2011. PMid:20367394. http://dx.doi. org/10.3109/11038120903578791

ERIKSSON, G.; THAM, K.; FUGL-MEYER, A. R. Couples' happiness and its relationship to functioning in everyday life after brain injury. Scandinavian Journal of Occupational Therapy, Stockholm, v. 12, n. 1, p. 40-48, 2005. http://dx.doi.org/10.1080/11038120510027630

ERLANDSSON, L. K.; EKLUND, M. Women's experiences of hassles and uplifts in their everyday patterns of occupations. Occupational Therapy International, Malden, v. 10, n. 2, p. 93-114, 2003. http:// dx.doi.org/10.1002/oti.179

GALHEIGO, S. M. O cotidiano na terapia ocupacional: cultura subjetividade e contexto histórico-social. Revista Terapia Ocupacional USP, São Paulo, v. 14, n. 3, p. 104-109, 2003.

GALVÃO, C. M.; SAWADA, N. O.; TREVIZAN, M. A. Revisão sistemática: recurso que proporciona a incorporação das evidências na prática da enfermagem. Revista Latino Americana de Enfermagem, Ribeirão Preto, v. 12 , n. 3, p. 549-556, 2004. http://dx.doi.org/10.1590/ S0104-11692004000300014

HASSELKUS, B. R. The world of everyday occupation: real people, real lives. American Journal of Occupational Therapy, Bethesda, v. 60, n. 6, p. 627-640, 2006. http:// dx.doi.org/10.5014/ajot.60.6.627

HASSELKUS, B. R.; MURRAY, B. J. Everyday occupation, well-being, and identity: the experience of caregivers in families with dementia. American Journal of Occupational Therapy, Bethesda, v. 61, n. 1, p. 9-20, 2007. http://dx.doi.org/10.5014/ajot.61.1.9

HELLER, A. O cotidiano e a história. São Paulo: Paz e Terra, 2000.

HELLER, A. Sociología de la vida cotidiana. Barcelona: Península, 2002. 
JOHANSSON, U.; HOGBERG, H.; BERNSPANG, B. Participation in everyday occupations in a late phase of recovery after brain injury. Scandinavian Journal of Occupational Therapy, Stockholm, v. 14, n. 2, p. 116-125, 2007. PMid:17538856. http://dx.doi. org/10.1080/11038120601095093

LARSON, E.; EYE, A. V. Beyond flow: Temporality and participation in everyday activities. American Journal of Occupational Therapy, Bethesda, v. 64, n. 1, p. 152-163, 2010.

LARSSON, A.; HAGLUND, L.; HAGBERG, J. Doing everyday life - experiences of the oldest old. Scandinavian Journal of Occupational Therapy, Stockholm, v. 16, n. 2, p. 99-109, 2009. PMid:18821446. http://dx.doi. org/10.1080/11038120802409762

LINDÉN, C.; BJÖRKLUND, A. Living with rheumatoid arthritis and experiencing everyday life with TNF- $\alpha$ blockers. Scandinavian Journal of Occupational Therapy, Stockholm,v. 17, n. 4, p. 326-334, 2010. PMid:20001643. http://dx.doi. org/10.3109/11038120903480055

LÖFQVIST, C. et al. Very old Swedish women's experience of mobility devices in everyday occupation: a longitudinal case study. Scandinavian Journal of Occupational Therapy, Stockholm, v. 16, n. 3, p. 181-192, 2009. PMid:19085321. http://dx.doi. org/10.1080/11038120802613108

LOPES, R. E.; GARCIA, D. B. Problemas e perspectivas escolares e de trabalho no cotidiano dos meninos e meninas trabalhadores da UFSCar. Cadernos de Terapia Ocupacional da UFSCar, São Carlos, v. 18, n. 3, p. 247-261, 2010.

LUVIZARO, N. A.; GALHEIGO, S. M. Considerações sobre o cotidiano e o habitar de crianças e adolescentes em situação de acolhimento institucional em abrigo. Revista Terapia Ocupacional da USP, São Paulo, v. 22, n. 2, p. 191-192, 2011.

MAGALHÃES, L.; GALHEIGO, S. M. Enabling international communication among Brazilian occupational therapists: seeking consensus on occupational terminology. Occupational Therapy International, Malden, v. 17, n. 3, p. 113-124, 2010. PMID: 20564687.

MARGOT-CATTIN, I.; NYGARD, L. Access technology and dementia care: influences on resident's everyday lives in a secure unit. Scandinavian Journal of Occupational Therapy, Stockholm, v. 13, n. 2, p. 113-124, 2006. http://dx.doi.org/10.1080/11038120600673056

NÄTTERLUND, B. S. A new life with aphasia: everyday activities and social support. Scandinavian Journal of Occupational Therapy, Stockholm, v. 17, n.
2, p. 117-129, 2010. PMid:20370533. http://dx.doi. org/10.3109/11038120902814416

ÖHMAN, A.; JOSEPHSSON, S.; NYGARD, L. Awareness through interaction in everyday occupations: experiences of people with Alzheimer's disease. Scandinavian Journal of Occupational Therapy, Stockholm, v. 15, n. 1, p. 43-51, 2008. PMid:17852957. http://dx.doi.org/10.1080/11038120701441080

PERSSON, M.; ZINGMARK, K. Living with a person with Alzheimer's disease: experiences related to everyday occupations. Scandinavian Journal of Occupational Therapy, Stockholm, v. 13, n. 4, p. 221-228, 2006. http:// dx.doi.org/10.1080/11038120600691066

RABER, C. et al. A phenomenological study of volition in everyday occupations o folder people with dementia. The British Journal of Occupational Therapy, London, v. 73, n. 11, p. 498-506, 2010. http://dx.doi.org/10.4276/ $030802210 X 12892992239116$

SALLES, M. M.; BARROS, S. Reinternação em hospital psiquiátrico: a compreensão do processo saúde/doença na vivência do cotidiano. Revista da Escola de Enfermagem da USP, São Paulo, v. 41, n. 1, p. 73-81, 2007. http://dx.doi. org/10.1590/S0080-62342007000100010

SALLES, M. M; MATSUKURA. T. S. Estudo de revisão sistemática sobre o uso do conceito de cotidiano no campo da Terapia Ocupacional no Brasil. Cadernos de Terapia Ocupacional da UFSCar, São Carlos, v. 21, n. 2, p. 265-273, 2013.

TOLLÉN, A.; FREDRIKSSON, A.; KAMWENDO, K. Elderly persons with disabilities in Sweden: their experiences of everyday life. Occupational Therapy International, Malden, v. 15, n. 3, p. 133-149, 2008. PMid:18496788. http://dx.doi.org/10.1002/oti.254

WERNGREN-ELGSTRÖM, M.; BRANDT, A.; IWARSSON, S. Everyday activities and social contacts among older deaf sign language users: relationships to health and well-being. Occupational Therapy International, Malden, v. 13, n. 4, p. 207-223, 2006. PMid:17623373. http://dx.doi.org/10.1002/oti.218

WRIGHT-ST CLAIR, V.; KERSE, N.; SMYTHE, E. Doing everyday occupations both conceals and reveals the phenomenon of being aged. Australian Occupational Therapy Journal, Richmond, v. 58, n. 2, p. 88-94, p. 88-94, 2011. PMid:21418231. http://dx.doi.org/10.11 11/j.1440-1630.2010.00885.

YILMAZ, M. et al. Participation by doing: social interaction in everyday activities among people with schizophrenia. Scandinavian Journal of Occupational Therapy, Stockholm, v. 15, n. 3, p. 162-172, 2008. PMid:19180722. http://dx.doi. org/10.1080/11038120802022102 


\section{Contribuição dos Autores}

Mariana Moraes Salles realizou a concepção da pesquisa, a coleta e análise de dados, efetivou a organizaçáo dos resultados, discussão e a redaçáo do texto. Thelma Simôes Matsukura orientou todas as etapas do estudo, participou da concepção da pesquisa, contribuiu na discussão dos resultados e realizou revisão crítica do texto.

\section{Notas}

${ }^{1} \mathrm{O}$ presente artigo integra o projeto de pesquisa realizado durante estágio pós-doutoral de título "Vida cotidiana e saúde mental: contextualizando as ocupaçóes e o uso do tempo de usuários de centros de atençáo psicossocial”, desenvolvido no Programa de Pós-Graduação em Terapia Ocupacional, Universidade Federal de São Carlos. Pesquisa financiada pela FAPESP - Fundação de Amparo à Pesquisa do Estado de São Paulo - Processo no 2011/23424-5.

${ }^{2}$ Segundo o Dicionário Houaiss da Língua Portuguesa, o termo ordinário pode ser definido como algo que ocorre conforme ao costume, à ordem normal; que é comum e habitual; que se repete seguidamente, em intervalos regulares; que se faz presente a todo instante; é constante, assíduo e frequente.

${ }^{3}$ Foram pesquisados artigos escritos em língua inglesa, que foram produzidos em diferentes países. Não necessariamente o inglês era a língua oficial do país de origem do texto. Porém, cabe ressaltar que a literatura encontrada em língua inglesa geralmente é uma literatura produzida no mundo ocidental. Assim, quando o texto se refere aos países de língua inglesa ou literatura internacional, neste artigo está se referindo à literatura produzida a partir da cultura ocidental.

${ }^{4}$ Nesta metodologia, os participantes da pesquisa eram bipados 10 vezes ao dia, por quatro dias, e a cada toque do bip respondiam a um questionário e duas perguntas relacionados a suas ocupaçóes.

${ }^{5} \mathrm{O}$ paradigma da ocupação é colocado na fundamentação histórica da Terapia Ocupacional internacional, tendo sua origem nos Estados Unidos, e até os dias atuais esse paradigma apresenta grande influência para a profissão. No entanto, não é objetivo deste estudo realizar um aprofundamento sobre o conceito de ocupação.

${ }^{6}$ Segundo Horochovski e Meirelles (2007), empoderar é o processo pelo qual indivíduos, organizaçóes e comunidades angariam recursos que lhes permitam ter voz, visibilidade, influência e capacidade de ação e decisão.

${ }^{7}$ Fonte: HOROCHOVSKI, R. R.; MEIRELLES, G. Problematizando o conceito de empoderamento. In: SEMINÁRIO NACIONAL: MOVIMENTOS SOCIAIS, PARTICIPAÇÃO E DEMOCRACIA, 2., 2007. Florianópolis. Anais ... Florianópolis: Núcleo de Pesquisa em Movimentos Sociais - NPMS, 2007. Disponível em: <http://www.sociologia. ufsc.br/npms/rodrigo_horochovski_meirelles.pdf>. Acesso em: 9 dez. 2013. 